\title{
Spatial regression analysis for discovering quality living index (QLI) in Asia
}

\author{
Devina Gilar Fitri Ayu Sumardi ${ }^{1, *}$, Tuti Purwaningsih ${ }^{2}$ \\ Department of Statistics, Faculty of Mathematics and Natural Science, Islamic University of Indonesia \\ ${ }^{1} 15611107 @$ students.uii.ac.id *; ${ }^{2}$ tuti.purwaningsih@uii.ac.id \\ * corresponding author
}

\begin{abstract}
ARTICLE INFO
ABSTRACT

Article history

Received December 21, 2017

Revised January 17, 2018

Accepted February 4, 2018

Keywords

Quality of life index

Asia

Spatial regression

Mapping

QGIS

The quality of life that is synonymous with welfare lately much discussed. Survival or quality of life is an important issue in the economy and political knowledge. Quality of life describes the achievement of an ideal human life or in accordance with the desired. The quality of life index (IKH) provides a comprehensive ranking of the quality of life of a society in a country around the world. According to katadata news and research in 2016, the quality of life in 5 Southeast Asian countries is ranked lowest. The research finds that there are regional imbalances based on the indices of quality of life in 2018. Therefore, countries in Southeast Asia need to be genjotic in all areas to boost contributions to the quality of life in the country, as Dominic Volek, Southeast Asia chief in Henley \& Partners Singapore. In this study we use the data from numbeo.com to see the value of quality indices in Asia in 2018 with various supporting indicators such as purchasing power index, security index, health care index, cost of living index, property price to income ratio, time index travel traffic, pollution index, and climate index. Where this study aims to determine how much influence the indicators that have been determined to calculate the CPI, knowing the best spatial regression model that can be used and determine whether there is asi gap in the region of Asia. The results of this study hope can be useful information for the community and a reference to make policy by the state officials in the field, but it can be a research material that can be developed again to see the difference and development of quality of life index in each country in Asia next year.
\end{abstract}

This is an open access article under the CC-BY-SA license.

\section{Introduction}

Quality of life that is identical with welfare, lately much discussed. Survival or quality of life is an important issue in the economy and political knowledge. Quality of life is generally measured by social and economic factors [1], [2]. Quality of life is a person's subjective feelings about his wellbeing, based on his or her current life experience as a whole. Quality of life describes the achievement of an ideal human life or in accordance with the desired. The quality of life index provides a comprehensive ranking of the quality of life of a society in a country around the world [3]. To ensure a high level of reliability, a wide range of measurable data is used to measure the opportunities and limitations imposed by individual countries.

Many scientists and world organizations have formulated indicators used in measuring the quality of life index, which is calculated based on health index, material welfare, feel of one part of local society, occupation and productive activity, welfare emotional, relationships with family and friends, as well as personal safety in the community in the country [4].

Quality of life is usually used to evaluate the general welfare of individuals and society, the term is used in a variety of contexts, including in the field of International development. On an 
internationally known scale the Millennium Development Goals (MDGs), agreed upon by world leaders in the 2000 Summit [5]. The MDG is a commitment of the international community, especially the developing world, to the vision of development [5], [6]. According to katadata news and research in 2016, the quality of life in 5 Southeast Asian countries is ranked lowest. Based on the Numbeo Quality Life Index, Vietnam became the worst-quality country of life from 61 countries surveyed in mid-2016. Indonesia stands at 57th place with an index value of 66.39. While countries from continental Europe and Australia occupy the top 5. Denmark became the country with the best quality of life with a score of 201.53 [7]. Index value is the result of estimation of quality of life with various factors, one of which is the environment and safety. Therefore, countries in Southeast Asia need to be genjotic in all areas to boost contributions to the quality of life in the country.

In this study, we took the Asian region as a limitation of research area to determine the CPI level of each country. According to Republika.co.id, the quality of life is good to be everyone's dream. But the good parameters of poor quality of life are different indicators. In this study we use the data from numbeo.com to see the value of quality indices in Asia in 2018 with various supporting indicators such as purchasing power index, security index, health care index, cost of living index, property price to income ratio, time index travel traffic, pollution index, and climate index. Under the title of "Influence Analysis on Level of Quality of Life (QLI) Index in Asia 2018 On The Determinants of QLI Using Spatial Regression With Geodes And QGis" This study aims to find out how much influence the indicators that have been determined to calculate the CPI, knowing the model the best spatial regression that can be used and know whether there is an imbalance in the region of Asia. Where the results of this study hope can be useful information for the community and a reference to make policy by state officials in the field, but it can be a research material that can be developed again to see the difference and development of quality of life index in each country in Asia for next year.

The purposes of this research is to find out the quality of life of Asian countries in 2018 is seen from the quality of life index and the various indicators. Discover the existence of indicators that significantly affect the quality of life index in Asia with the spatial regression model. The latest one is to find out the imbalance of Asian countries based on the quality of life index in 2018.

\section{Method}

The research used by type of data and its analysis is quantitative research, which is research which its analysis more focus on numerical data which is processed by spatial regression method using GEODA software [8], [9]. In this study, tests on 9 secondary data obtained from www.numbeo.com, which contains the world's largest user database that contributes data about cities and countries around the world. Numbeo provides current and timely information on world living conditions including living costs, housing indicators, health care, traffic, crime and pollution. Data used in this research is data in Asia region with variables as in Table 1.

Table 1.

Quality of Life Indicators [10]

\begin{tabular}{cccc}
\hline No & Variable & Variable's Code & Variable Type \\
\hline 1 & Quality of life index & QLI & Dependent \\
\hline 2 & Purchasing power index & Purpower & Independent \\
\hline 3 & Safety index & Safety & Independent \\
\hline 4 & Health care index & Health & Independent \\
\hline 5 & Costs of living index & Cost & Independent \\
\hline 6 & Property price to income ratio & Proprice & Independent \\
\hline 7 & Traffic commute time index & Traffic & Independent \\
\hline 8 & Pollution index & Pollution & Independent \\
\hline 9 & Climate index & Climate & Independent \\
\hline & & &
\end{tabular}




\section{Result and Discussion}

Factors affecting world gas prices include purchasing power index, security index, health care index, cost of living index, property price to revenue ratio, traffic time travel index, pollution index, and climate index. To answer these problem there are some results and the discussion.

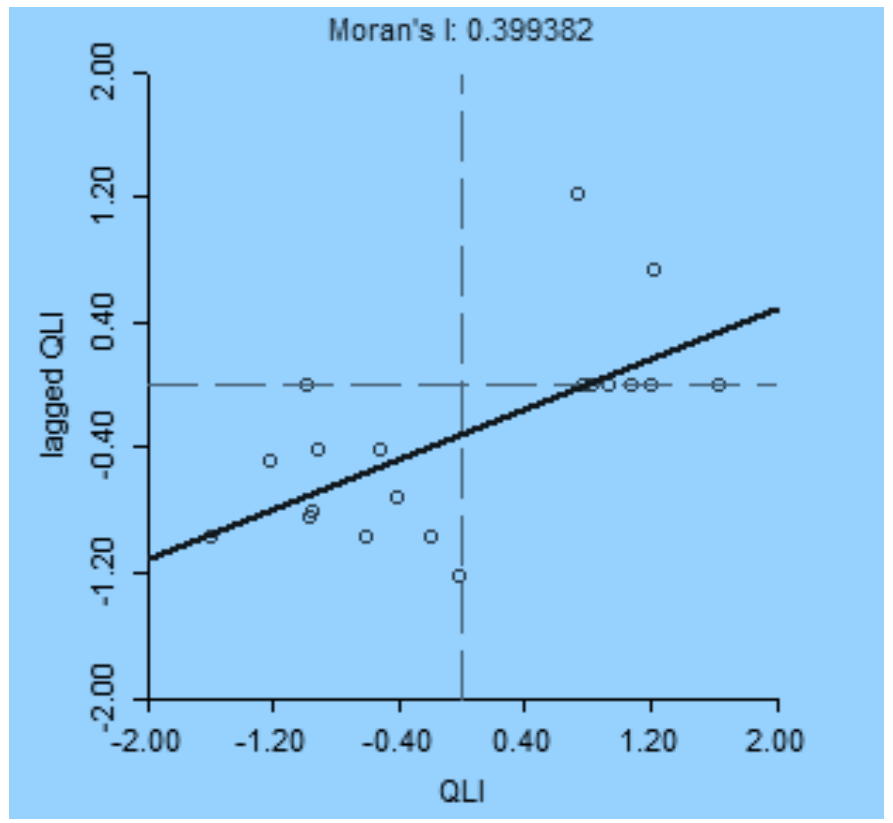

Fig. 1.Moran's Index Graph

Figure 1 is the output of Global Moran's I Index used to determine whether there is spatial autocorrelation in gasoline price data. From the output note that the value of moran index for variable gasoline price that is equal to 0.399382 , the value is in the range $0<\mathrm{I} \leq 1$ which indicates the existence of positive spatial autocorrelation, correlation included in correlation level is, because the closer to zero the correlation will be weaker. Means it can be concluded that the inter-country one with another does not have a similarity in value or indicates that the data is not in groups. However, moran test statistics have a weakness that is less sensitive in detecting spatial autocorrelation, because it requires a high error rate. It is therefore advisable to try other methods such as classical methods, Lag, and errors.

In linear regression there are several assumptions that must be met such as normality, multicollinearity, heteroscedasticity, and autocorrelation. From the test results with Geoda obtained statistical test results which can be seen in Figure 2. The next phase is test the normality use the kolmogrorov smirnov non-parametric test (K-S) aims to test the normal distribution regression model. In the Jarque-bera test obtained $p$-value value significantly equal to $0.63946>\alpha(0.05)$ so that the failure to reject $\mathrm{H} 0$ then the error data is normally distributed.

The Breusch-Pagan test detects whether or not heteroscedasticity is present. Models are considered good in the absence of heteroscedasticity. From result of Breusch-Pagan test using GeoDa obtained $\mathrm{p}$-value value for this model is equal to $0,61894>\alpha(0,05)$, so it can be said insignificant, using level of significance 0,05 from existing data all model failed reject $\mathrm{H} 0$ means the regression model does not contain homoscedasticity. Thus, no spatial effects are found in the data, so the influence of the location does not need to be included in the model, but this data can be used with the GWR method to see the factors that affect the quality of life index with heteroscedasticity data. 

Vol. 2, No. 1, March 2018, pp. 1-7

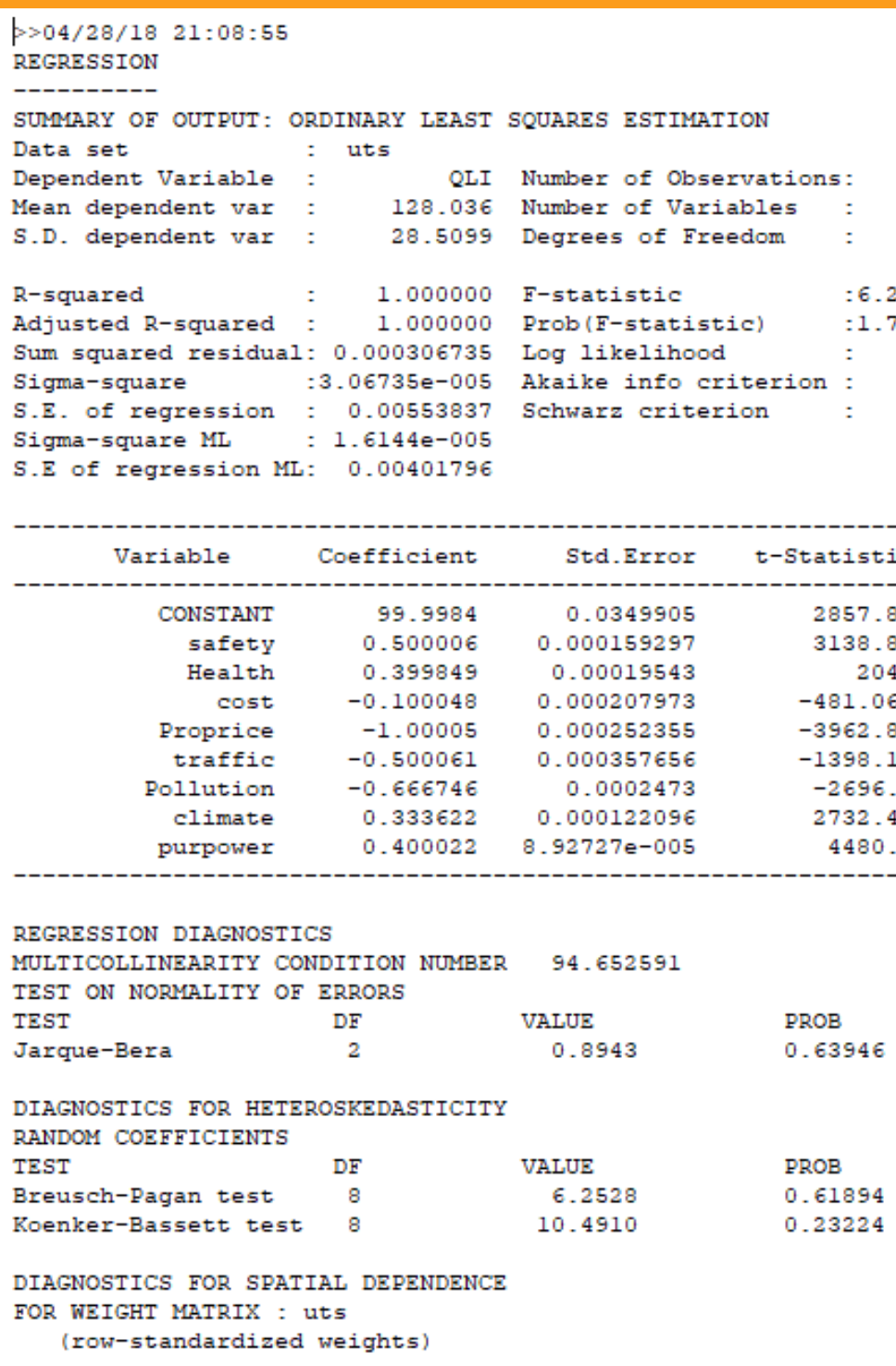

Fig. 2.Output of OLS regression with Geoda

Detection of autocorrelation in spatial data using Moran's test I. Table 2 is the output of Moran's I using Geoda program is -0.5568 . Where the value $\mathrm{I}=0.57767>0$ so there is a negative autocorrelation, this means the data patterns collect and form clusters (clusters). Next will be tested autocorrelation between locations using Moran's test I. The hypothesis tested are H0: $\mathrm{I}=0$ (There is no autocorrelation between locations) and H0: $\mathrm{I} \neq 0$ (There is autocorrelation between locations).

Table 2. Moran's Test Result

\begin{tabular}{cccc}
\hline $\begin{array}{c}\text { Spatial } \\
\text { Dependence }\end{array}$ & Value & P-value & Decision \\
\hline Moran's I & $-0,5568$ & 0,57767 & Reject $\mathrm{H}_{0}$ \\
\hline
\end{tabular}

Based on the analysis of Moran's I it is known that the value of probability Moran's I of $0.57767>$ $\alpha$, so fail to reject H0. It means there is no autocorrelation between locations so that the assumption of freedom error is met. In this case actual spatial regression cannot be used for spatial nonautocorrelation data. 
The value of R-square or coefficient of determination is used to find out how big the independent variable can explain the dependent variable / contribution influence independent variable (independent) to dependent variable (dependent). The R-square value only ranges from 0-1, getting closer to 1 the stronger the effect, as found in this case. From the results of spatial regression output in Figure 5.2 note that the value of R-square obtained that is equal to 1 , it means there is the influence of independent variables are very strong to explain the dependent variable.

To see which factors affect the quality of life index can be seen from the value of probability variables as in the OLS regression output in Figure 5.1 above. From the results it is known that all independent variables have the same value that is $0.000<\alpha(0.05)$ which means all variables assumed to reject $\mathrm{HO}$ where all independent variables significantly influence the quality of life index in Asia.

The next stage is choosing The Best Method in Spatial Regression Models in addition to OLS. The test to know which method can be used to model the quality of life index number in Asia can be seen from the Lagrange multiplier value of 3 methods besides OLS i.e. SAR, SEM, and SARMA presented in the Table 3.

Table 3. $\quad$ Lagrange Multiplier Test Result

\begin{tabular}{ccc}
\hline Method & Lagrange Multiplier Value & Decision \\
\hline SAR & $0,51982>\alpha$ & Fail to Reject $\mathrm{H}_{0}$ \\
\hline SEM & $0,17226>\alpha$ & Fail to Reject $\mathrm{H}_{0}$ \\
\hline SARMA & $0,32026>\alpha$ & Fail to Reject $\mathrm{H}_{0}$ \\
\hline
\end{tabular}

From the results in Table 3 it can be concluded that of the three models of spatial regression that all three are assumed to reject failure H0. It means that there is no regression model that can be used other than OLS, and because this data is homogeneous, it is better to do regression test using GWR method.

Data visualization includes region mapping, and presents plot / graph data. This is done to see clearly which countries have low and high quality of life, and to see regional imbalances in Asia based on the quality of life index of 2018. Based on Figure 3, it is known based on existing legend, that dark green color depicts low quality of life and medium red, while pink and light green in a row depicts the level of quality of life is getting higher. Of the 19 countries in Asia in this study, the five countries with highest quality of life index are Japan, United Arab Emirates, Taiwan, Qatar and South Korea. While the five countries with the lowest quality of life index are in Vietnam, Iran, Philippines, China and Pakistan. From mapping of quality of life index is also known in Asia there is imbalance of quality of life, where it is seen that the average country with high quality of life index aligned with countries with low quality of life, so it is very visible differences and disparities between regions. Therefore, special attention is needed by the governments of each country in Asia to be able to improve each other's quality of life in their country which still has a low quality of life index so that Asia can be an example by other areas in an effort to improve the index of quality of life and good cooperation.

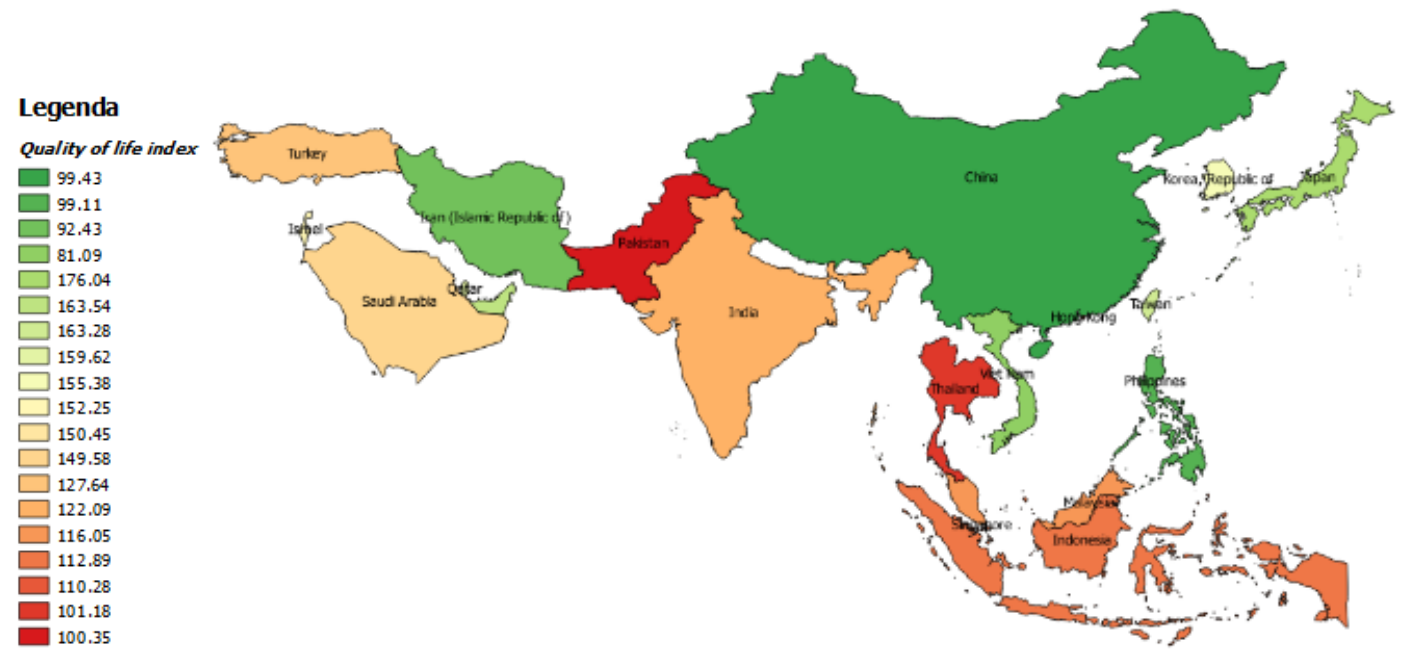

Fig. 3.Mapping of quality of life index in Asia 2018 


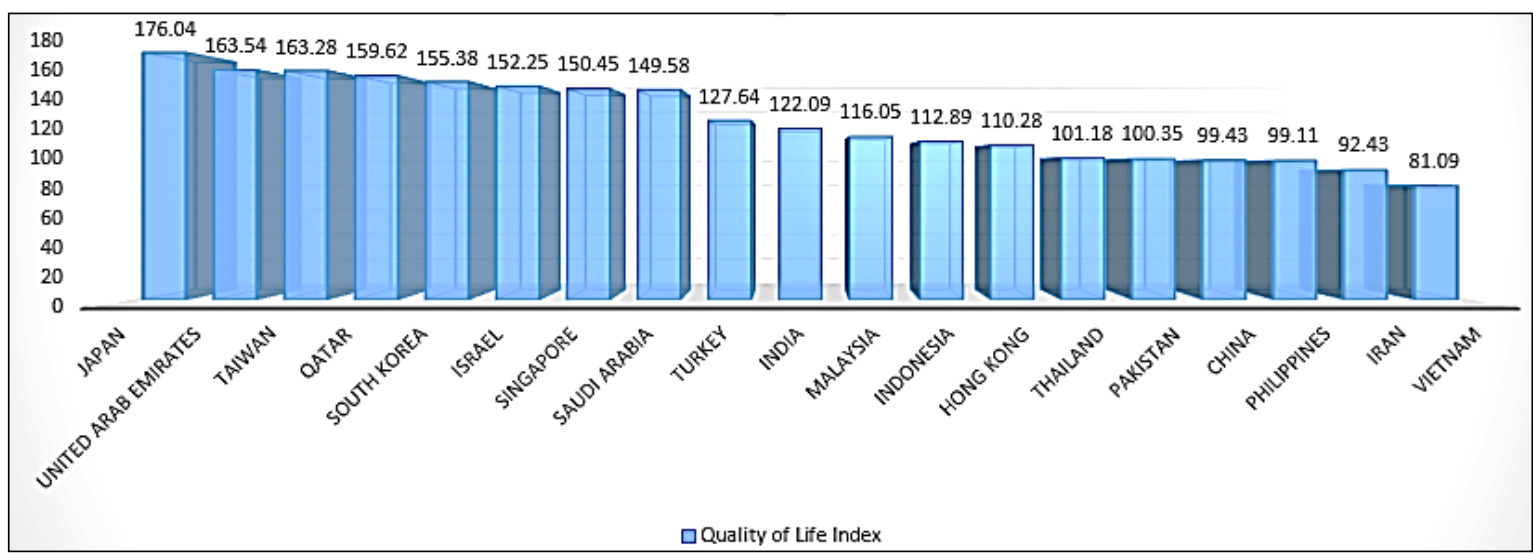

Fig. 4. The 2018 Life Quality Index graph in Asia

Figure 4 is used to determine the level of quality of life index of countries in Asia as a whole. A higher quality of life index signifies better community welfare, this index is measured using an empirical formula that takes into account purchasing power (higher up better), pollution index (lower is better), ratio of goods price to income (lower is better ), a higher (better) index of living costs, a safety index (higher is better), health care index (higher is better), traffic travel time index (lower is better) and climate index (higher is better) .

\section{Conclusion}

Based on the results of the analysis that has been done it can be concluded that the quality of life of Asian countries in 2018 is seen from the index of quality of life and the various indicators in the not too high and not too low. The highest value of life index value of 176.04 is owned by Japan and the lowest is 81.09 is owned by Vietnam. Indicators that have a significant effect on the quality of life index in Asia are all independent variables with p-value is 0.000 <alpha $(0.05)$ from the results obtained, the factors that significantly affect is all the independent variables used in research These are purchasing power index, security index, health care index, cost of living index, property price to revenue ratio, traffic time travel index, pollution index, and climate index. The spatial regression model that can be used in this research does not exist, because the data is heterogeneous and the Lagrange multiplier test value of each method i.e. SAR, SEM, and SARMA is greater than 0.05 which is assumed that the model cannot be used in all methods. In the result of visualization of quality of life index in Asia in 2018, there is an imbalance of prosperity among countries in Asia, because the average country with high quality of life index is aligned with countries with low quality of life.

\section{References}

[1] M. Nussbaum and A. Sen, The quality of life. Oxford University Press, 1993.

[2] D. F. Cella and D. S. Tulsky, "Measuring quality of life today: methodological aspects," Oncol. (willist. Park. NY), vol. 4, no. 5, pp. 29-38, 1990.

[3] A. J. Carr, B. Gibson, and P. G. Robinson, "Is quality of life determined by expectations or experience?," Bmj, vol. 322, no. 7296, pp. 1240-1243, 2001.

[4] M. R. Hagerty et al., "Quality of life indexes for national policy: Review and agenda for research," Bull. Sociol. Methodol. Méthodologie Sociol., vol. 71, no. 1, pp. 58-78, 2001.

[5] J. D. Sachs and J. W. McArthur, "The millennium project: a plan for meeting the millennium development goals," Lancet, vol. 365, no. 9456, pp. 347-353, 2005.

[6] P. Travis et al., "Overcoming health-systems constraints to achieve the Millennium Development Goals," Lancet, vol. 364, no. 9437, pp. 900-906, 2004. 
[7] Numbeo, "Quality of Life Index for Country 2016 Mid-Year," 2018. [Online]. Available: https://www.numbeo.com/quality-of-life/rankings_by_country.jsp?title=2016-mid. [Accessed: 20-Apr2018].

[8] L. Anselin, I. Syabri, and Y. Kho, "GeoDa: an introduction to spatial data analysis," Geogr. Anal., vol. 38, no. 1, pp. 5-22, 2006.

[9] J. Odland, Spatial autocorrelation. Newbury Park, CA: Sage publication, 1988.

[10]Numbeo, “Asia: Quality of Life Index by Country 2018," 2018. [Online]. Available: https://www.numbeo.com/quality-of-life/rankings_by_country.jsp?title=2018\&region=142. [Accessed: 20-Apr-2018]. 